\title{
¿Felices los pobres (Mt 5,3)? \\ Evidencia empírica para confrontar una promesa evangélica
}

\author{
FRANKLIN IBÁÑEZ* \\ Universidad del Pacífico (Perú) \\ fe.ibanezb@up.edu.pe \\ PEDRO MATEU** \\ Universidad del Pacífico (Perú) \\ pf.mateub@up.edu.pe \\ ENRIQUE VÁSQUEZ*** \\ Universidad del Pacífico (Perú) \\ vasquez_ee@up.edu.pe \\ JAVIER ZÚÑIGA**** \\ Universidad del Pacífico (Perú) \\ zuniga_jj@up.edu.pe
}

\section{Resumen}

En las Bienaventuranzas, la promesa de felicidad a los pobres genera cierto debate ya que es obvio que en sentido económico ellos afrontan una vida bastante difícil. El artículo investiga la relación entre felicidad, religiosidad y situación económica, pobreza o riqueza, en dos grupos de distritos del Perú: los más pobres y los más ricos, los extremos. Por una parte, la versión de Lucas, "felices los pobres", parece incorrecta en sentido empírico pues los pobres reales son menos felices que los ricos. En cambio, la versión de Mateo, "felices los pobres de espíritu", sí parece tener sustento empírico, al menos si se le comprende en el modo en que lo hace Gustavo Gutiérrez. En suma, un trabajo de campo basado en encuestas respaldaría la interpretación de Gutiérrez sobre la felicidad de quienes se identifican como pobres espirituales.

Palabras clave: Felicidad, bienaventuranzas, pobreza, teología de la liberación, Gustavo Gutiérrez.

$$
\begin{gathered}
\text { Happy are the Poor (Mt 5:3)? } \\
\text { Empirical evidence to assess a gospel promise }
\end{gathered}
$$

\begin{abstract}
In Beatitudes, the promise of happiness to the poor is polemic since it is obvious that they face very hard living conditions. This paper focus on the relationship between happiness, religiousness and economic situation, poverty or wealth, in two groups of districts in Peru: the poorest and the richest ones, ie the opposite. While Luke's statement "Happy are the poor" seems to be incorrect in an empiric sense -real poor people are often less happy than rich ones-, Matthew's statement "Happy are the poor in spirit" seems to find empirical support, at least if it is understood as Gustavo Gutierrez does. In summary, fieldwork made on surveys endorses Gutierrez interpretation on the happiness of those who identified themselves as spiritual poor.
\end{abstract}

Key words: Happiness, beatitudes, poverty, liberation theology, Gustavo Gutierrez:

\footnotetext{
* Doctor en Filosofía (Pontificia Università Gregoriana, Italia).

** Doctor en Evaluación (Western Michigan University, EE.UU.)

*** Doctor en Política (Oxford University, Reino Unido)

**** Doctor en Matemáticas (University of Minnesota, EE.UU.)
} 


\section{INTRODUCCIÓN}

El estudio de la felicidad, satisfacción vital o bienestar subjetivo -entre otros términos frecuentemente utilizados de modo indistinto- viene despertando gran interés entre las más diversas disciplinas. Con dos décadas de diferencia, los trabajos de Veenhoven (1997), Prasoon \& Chaturvedi (2016) reseñan el creciente y prolijo interés académico por la felicidad entendida de múltiples formas. En el desarrollo de esas investigaciones, la religión aparece como uno de los factores más importantes para comprender qué hace felices a las personas. Hace décadas se notó la relación positiva entre religión y felicidad (Cox \& Hammonds, 1989; Hadaway, 1978; Moberg, 1979). Tal descubrimiento continúa siendo refrendado en las más diversas poblaciones que incluso profesan religiones diferentes. Así sucede, por ejemplo, para el sur cristiano de Estados Unidos (Soydemir, Bastida \& Gonzales, 2004), o escenarios musulmanes como Kuwait (AbdelKhalek, 2007) y Líbano (Abdel-Khalek, 2014).

En un nivel global, el primer Informe Mundial de la Felicidad, auspiciado por las Naciones Unidas, señala que al menos el 68\% de la población adulta del planeta considera que la religión es importante en sus vidas y, por tanto, para su felicidad (Helliwell, Layard \& Sachs, 2012). Además, según el mismo reporte, en aquellos países donde la vida es especialmente dura, había muchas más emociones positivas que negativas entre aquellas personas que son religiosas, mientras que esa diferencia no existía en países donde la vida es más llevadera. La religión ayudaría especialmente a los pobres a ser más felices. Por su parte, Inglehart (2010), con base en la Encuesta Mundial de Valores, sostiene que la religión, aun cuando se observe en ciertas geografías una tendencia hacia la secularización, sigue siendo importante para la felicidad. Al analizar la data recogida en 93 de países por la Encuesta Mundial de Valores, Gundlach \& Opfinger (2013) apoyan la tesis de Inglehart.

Los estudios que han tratado de comprender por qué o en qué modo la religión es importante para la felicidad han ensayado explicaciones diversas y a veces contradictorias entre ellas ${ }^{1}$. A diferencia de aquellos estudios, el presente artículo ofrece una novedad que se relaciona con la visión

\footnotetext{
1 Reseñemos algunos ejemplos. Por un lado, Greeley \& Hout (2006) concluyen que la correlación positiva entre religión y felicidad se produce porque la religión ofrece identidad, una red social de apoyo y sentimiento de cercanía a Dios. Estos elementos se activan cuando la persona participa de la comunidad o la vivencia religiosa. Las creencias por sí solas, que están dormidas o pasivas, no elevan la felicidad. Por su parte, Ellison (1991) señala que la relación entre religión y bienestar subjetivo es directa en cuatro formas: al ofrecer soporte e integración social, al relacionar al creyente con la divinidad, al otorgar sistemas de sentido y una existencia coherente, y al proveer específicos
} 
de la Teología de la liberación. Se trata de relacionar estudios de campo, encuestas, con un elemento central de aquella teología: la felicidad de los pobres. En el Evangelio, y la Biblia en general, existen varios usos del término pobre. Por ejemplo, Jesús dice "felices los pobres" (Lc 6,20)" y "felices los pobres de espíritu" (Mt 5,3). De manera muy sucinta podrían entenderse de esta manera: para Lucas la pobreza como carencia material que connota exclusión social y para Mateo la pobreza como actitud espiritual. ¿Cómo estos sentidos de pobreza están relacionados con la felicidad según reportan las personas reales, sean creyentes o no? Especialmente interesa la llamada pobreza espiritual pues no parece común ni fácil captarla a través de instrumentos de medición o trabajos de campo. Sin embargo, estos podrían ofrecer soporte empírico para la teología y para una particular interpretación de la pobreza espiritual ¿Es una actitud frente a la posesión material en nombre de una riqueza más bien espiritual? ¿ $\mathrm{O}$ un compromiso con quienes padecen la pobreza material? En este artículo, tras determinar valores concretos con los que se puede identificar dos tipos de pobres espirituales, se procura determinar quiénes son más felices y, por tanto, qué interpretación de tal pobreza sería más coherente con la experiencia de las personas.

Entonces, el presente artículo no se concentra tanto en una nueva discusión exegética de la felicidad en las bienaventuranzas, sino que ensaya una vía inédita pues, según la búsqueda de los investigadores, no ha habido otro intento por ofrecer respaldo empírico a una interpretación teológica de la felicidad en las bienaventuranzas. Hace un siglo, con el repunte de las ciencias sociales, Pratt se preguntaba con qué método se podría brindar apoyo a la teología (1920). Actualmente, la producción en esa línea viene creciendo a tal punto de instituir la reconocida revista Journal of Empirical Theology $y^{2}$. Los esfuerzos por encontrar soporte empírico para ciertos planteamientos teológicos tampoco son ajenos en el ámbito hispano ${ }^{3}$.

El artículo se desarrolla en cuatro partes. En la primera sección, se expone una visión panorámica de la discusión bibliográfica en torno a la felicidad de los pobres espirituales. En la segunda, se presentan consideraciones generales sobre la relación empírica entre felicidad y religión, y particularmente el resultado de dicha relación en los distritos más pobres

patrones de organización y estilo de vida. Finalmente, Lim \& Putman (2010) creen que el elemento fundamental para explicar la correlación positiva es la pertenencia a una comunidad o red social activa y gratificante.

2 https://brill.com/view/journals/jet/jet-overview.xml. La base teórica que sustenta la propuesta de la revista se encuentra en Francis, Robbins \& Astley (2009). Para una revisión que narra la evolución en Estados Unidos, véase Deanis (1990).

3 Algunas publicaciones recientes en lengua española Schickendantz (2017) y CerdaPlanas (2019). 
y más ricos del Perú. En la tercera parte, se exploran algunas interpretaciones de Gustavo Gutiérrez sobre la expresión "pobreza espiritual”. En la cuarta, se traducen esas interpretaciones de pobreza espiritual a valores medibles por instrumentos internacionales para determinar si la frase "felices los pobres de espíritu" (Mt 5,3) concuerda con los datos obtenidos en encuestas. ¿Son felices los pobres espirituales? ¿En qué sentido?

\section{LA POBREZA ESPIRITUAL EN CUESTIÓN}

Para el presente artículo, se propone centrar la discusión en un eje crucial para comprender la relación entre pobreza y felicidad: las bienaventuranzas, situadas en el centro del discurso y la misión de Jesús (Camacho, 1986). Llamar a alguien bienaventurado, del griego makários, significa felicitarle, considerarlo dichoso. En el mundo griego, inicialmente solo los dioses y semidioses podían ser llamados felices, makárioi, pues solo ellos estaban por encima de los avatares e infortunios que el hombre común atraviesa en la tierra (Lefka, 2016). Sin embargo, la tradición griega evoluciona y concede cierto grado de felicidad a los héroes, quienes poseen un origen divino y cumplen su deber, como Aquiles u Odiseo. En cambio, ya en tiempos de Platón (1988), Aristóteles (1985) y Epicuro (2012), por citar algunos nombres relevantes en la tradición filosófica, la felicidad es parcialmente asequible para quienes viven conforme a la razón. Estos tres pensadores estarían de acuerdo en que la felicidad es propia de los sabios, quienes saben guiar su vida, no la malgastan en placeres vanos. ${ }^{4} \mathrm{Si}$ la felicidad requiere un esfuerzo intelectual, no es para cualquiera, sino para un grupo selecto. Sócrates se mantenía a cierta distancia de ellos pues él no cesaba de interpelar a cualquier ciudadano a que examine su vida y procure vivir del mejor modo posible (Platón, 1981). Frente al mundo clásico, las bienaventuranzas utilizan el adjetivo "felices", makarioi, para otros sujetos: los pobres. El sujeto de las bienaventuranzas, a diferencia del mundo griego, no son los dioses, ni los semidioses, ni los héroes, ni los sabios, sino los pobres.

Las expresiones "felices los pobres" y "felices los pobres de espíritu" han generado un gran debate desde los primeros siglos del cristianismo. ¿Quiénes son? ¿Por qué son o serían felices? Mucho se ha escrito. La monumental obra de Dupont (1969a; 1969b; 1973) parecía dar a la cuestión

$4 \quad$ Se suele simplificar y malinterpretar a los epicúreos, como si recomendasen vivir entregados a los placeres a secas. De allí que históricamente se ha asumido que ellos priorizaban los placeres mundanos o carnales. En cambio, la escuela hedonista de Epicuro era muy consciente de esa crítica injusta y, más bien, proponía una vivencia reflexiva de los placeres, desde la prudencia (García, 2011). 
un carácter completo, sistemático y definitivo. Particularmente, respecto de la enigmática expresión de Mateo, "felices los pobres de espíritu", Dupont mismo señalaba: "La exégesis moderna ha estado perpleja hasta muy recientemente frente a la expresión 'pobres de espíritu'. Los manuscritos del Qunram han resuelto el problema al emplear esa expresión en contextos que no permiten dudas sobre su sentido" (1977: 50, cursivas nuestras). Quedaba así, en opinión de Dupont, despejado el significado en favor de una antigua tradición sostenida por los padres de la Iglesia que no pudieron fundamentar exegéticamente su interpretación. Ser "pobre de espíritu" significa llegar a ser una persona humilde interiormente. No es una condición gratuita, sino que requiere un esfuerzo consciente por inclinarse, abajarse o humillarse por razón de la fe en Dios.

Sin embargo, la cuestión no se ha cerrado y no pocos importantes matices se han alzado posteriores a la obra de Dupont. Betz (1995) sostiene que pobre en espíritu refiere a la persona que es consciente de la condición humana. Es ciertamente una forma de humildad: saber quién se es, en vez de vanagloriarse de quien no se es, como Sócrates atestiguó con su vida siglos antes en Atenas. Pero, a diferencia del filósofo griego, el cristiano pobre de espíritu que sabe quién es reposa su confianza en la misericordia de Dios. Hagner (1993) añade que Mateo ha captado con esa expresión la relación entre pobreza y piedad, una relación extendida en la época de Jesús. Si bien dicha frase no trata de espiritualizar a quienes son pobres en sentido social o económico, muchos de ellos en verdad viven espiritualmente en el sentido de no gozar de otro recurso que su esperanza en Dios. Por su parte, Neyrey (2005) señala que es posible ofrecer nuevas interpretaciones del sermón de la montaña a partir de los valores clave del mundo de Jesús: el honor y la vergüenza. Así, más que "felices los pobres", las bienaventuranzas podrían traducirse como "honorables los pobres", aunque ciertamente este sería un honor contracultural. Si pobre - ptojos- es quien ha perdido bienes y se encuentra necesitado o menesteroso, un pobre espiritual es quien ha perdido estatus social u honor del mundo por cuenta del evangelio.

No ha faltado otro tipo de aproximaciones con novedosas herramientas provenientes de las más diversas disciplinas. Una de estas experiencias viene de la aplicación del enfoque SIFT por sus siglas en inglés: sensing percibir, fijarse en aquello que se capta con los sentidos-, intuition -intuir significados y relaciones-, feeling -sentir o enfocarse en aquello que emociona o conmueve- y thinking - pensar racionalmente. Estas cuatro funciones psicológicas son derivadas de la teoría de Carl Jung. Cada una de aquellas, a su vez, se puede subdividir en una orientación introvertida o interior y una extrovertida o exterior. Francis, Strathie \& Ross (2019) han aplicado SIFT al estudio de las Bienaventuranzas para captar el modo en que los 
lectores se aproximan y los significados que prevalecen en ellos. Tras reunir a un grupo religioso en Inglaterra y darles a leer las Bienaventuranzas de Mateo, los autores analizan diversas reacciones e interpretaciones de los lectores según el tipo de función psicológica predominante en ellos. Así, por ejemplo, la palabra griega makarios produjo un enérgico impacto en el grupo donde predomina la función intuitiva introvertida, pero no fue un detonador para atraer experiencias de la historia personal, como sí sucedió en el grupo donde predomina la función sensitiva.

Finalmente, la relación entre la pobreza espiritual y la pobreza material, tal como la expondremos en la sección tercera en los términos de Gustavo Gutiérrez, puede encontrar analogías en otros autores, incluso de las más remotas latitudes. Citando los trabajos del jesuita Aloysius Pieris sobre teología de la liberación en Asia, Phan (1993) señala que podrían considerarse dos formas de pobreza: la forzada y la voluntaria. La primera es fruto de la injusticia; la segunda expresa solidaridad con quienes sufren la primera. De ese modo, la liberación puede verse como bidimensional. En términos de la pobreza voluntaria, significa una emancipación interior de una suerte de esclavitud espiritual -como el apego a los bienes del mundo-, mientras que en términos de la pobreza forzada, denota, más bien, liberación de las estructuras económicas y sociopolíticas opresoras. Algo semejante diremos de la relación entre la pobreza espiritual y la real.

\section{RELIGIÓN Y FELICIDAD}

El presente estudio parte de la "Encuesta de medición de los índices de felicidad, pobreza multidimensional y valores en dos Perus" realizada en el año 2017 y denominada en adelante Encuesta FPV. El trabajo de campo se realizó en diez distritos del Perú: los cinco más pobres y los cinco más ricos según el mapa de pobreza monetaria del Instituto Nacional de Estadística e Informática (INEI 2015) ${ }^{5}$. Desde tales distritos, se obtuvo una muestra de jefes de hogar: para los pobres 537 y para los ricos 406. A lo largo del texto las referencias a pobres y ricos, o construcciones sustantivas semejantes, deben comprenderse siempre como jefes de hogar de los cinco distritos más pobres y más ricos. A fin de poder realizar comparaciones eventuales con otros contextos, se aplicaron instrumentos internacionales cuya validez es bastante aceptada. Para medir la felicidad, se utilizó el Cuestionario de Felicidad de Oxford (Hills \& Argyle, 2002). Este consta de 29 ítems sobre una escala de 6 puntos. En la medida que las

\footnotetext{
$5 \quad$ El Perú se divide en 25 regiones; cada una de ellas, en provincias; estas a su vez, en distritos. El mapa del INEI consideró 1943 distritos en total. Para mayores detalles sobre el trabajo de campo, revisar Vásquez et al. (2021).
} 
preguntas eran muy difíciles de comprender y responder por la población entrevistada en el sector más pobre, se aplicó una versión resumida de 8 ítems que los propios creadores del instrumento recomiendan y se acortó la escala de 6 a 4. Utilizando técnicas de medición psicométricas, se estimaron los puntajes de felicidad de los jefes de hogar de ambos grupos. Luego, estos fueron transformados a una escala de 0 a 20 para facilitar su comprensión, ya que esta es común en la medición de rendimientos escolares del Perú, a diferencia de otros países que utilizan escalas del 1 al 10 o al 100. El cálculo de los puntajes de felicidad se describe en Mateu et al. (2020).

¿Puede este instrumento de medición captar la felicidad o dicha que el evangelio promete? Ciertamente no, sobre todo en lo que podríamos llamar su dimensión escatológica - de la cual hablaremos en la siguiente sección. Pero, ¿al menos la felicidad evangélica terrenal puede ser aprehendida por una encuesta? Probablemente ningún instrumento de medición capta plenamente la felicidad en sentido eudaimonista -según la tradición aristotélica- o hedonista -según la tradición epicúrea. La felicidad, no solo la cristiana sino la Felicidad, como la han concebido diversas tradiciones filosóficas y religiosas, escapa en parte a la medición. Los informes mundiales de felicidad lo admiten (Helliwell, Layard \& Sachs, 2012) al igual que todos quienes se empeñan seriamente en el asunto. Por ejemplo, uno de los límites más concretos del método empleado para este estudio es que las encuestas son mediciones subjetivas, es decir, reposan en la propia percepción del sujeto entrevistado. Otro obstáculo radica en su matematización. Y podríamos seguir.

De todos modos, el instrumento de Oxford es uno de los más reconocidos en parte porque es multidimensional. A diferencia de las mediciones más comunes de felicidad, que se centran en una sola pregunta o dimensión -sobre todo en la realización del proyecto personal de vida-, el instrumento de Oxford reúne al menos tres elementos importantes: presencia de emociones positivas, ausencia moderada de emociones negativas y evaluación suficientemente satisfactoria de la propia vida. Sobre la felicidad o bienaventuranza cristiana, dice Hagner que makarioi "describe la casi incomprensible felicidad de aquellos que participan en el Reino anunciado por Jesús. Más que felicidad en un sentido mundano, se refiere a la profunda e interna alegría de quienes han esperado largo tiempo la salvación prometida por Dios y quienes ahora comienzan a experimentar su cumplimiento" (1993: 91, traducción propia). ¿Cuánto de esta suprema o profunda felicidad es captada por aquellos tres elementos del instrumento de Oxford? ¿Podemos esperar razonablemente que quien ha sido tocado por el evangelio se sienta en esta vida realizado, sobrelleve las penurias, y mantenga cierta calma o alegría según el sentido común? Si la respuesta es 
sí, entonces el instrumento posee cierta validez. Es un límite real que debemos aceptar para el estudio.

La sociedad peruana es bastante religiosa. El Censo Nacional 2017 indagó la religión de las personas mayores a 11 años (INEI 2018b). Entre ellas el 76,0\% se identifica con la Iglesia Católica; el 14,1\%, con la Evangélica; el 4,8\%, con otra iglesia o religión (Cristiano, Adventista, Testigo de Jehová, Mormón, Israelita, Budismo, Judaísmo y Musulmán, entre otras) $;^{6}$ y finalmente el 5,1\% no sigue ninguna. En suma, el 94,9\% se considera creyente; y casi el $90 \%$, cristiano en alguna de sus formas.

Siendo un país marcadamente creyente, el Perú es un escenario interesante para analizar la "felicidad de los pobres", de la que se habla en las bienaventuranzas, porque presenta una tasa de pobreza monetaria de alrededor de 21,7\%; y de pobreza extrema cercana a 3,8\% (INEI, 2018a). Aunque los porcentajes de pobreza son significativos, el país ha registrado una de las tasas de crecimiento económico más altas y sostenidas en la región latinoamericana. No obstante, la pobreza persiste y la desigualdad económica también. De hecho, aunque las cifras oficiales hablen de una desigualdad decreciente y menor al promedio latinoamericano, tales cifras estarían subvaluadas y más bien aquella sería alta y creciente como sucede en el resto del mundo (Alarco, Castillo \& Leiva, 2019).

En otro documento, los autores del presente artículo expusimos hallazgos descriptivos sobre cómo los más pobres y los más ricos viven la religión (Ibáñez et al., 2020). Ambos extremos de la pirámide social peruana, particularmente el desposeído, se conciben a sí mismo como muy religiosos. Son además particularmente "cristianos", si se considera que la mayoría profesa tal religión o participa de la Iglesia católica o alguna Iglesia autodenominada cristiana o evangélica. Además, en ese mismo documento se describe estadísticamente la religiosidad de los encuestados a partir de un elemento objetivo, público u observable como la asistencia a misas y/o cultos, y un elemento subjetivo o privado como la práctica del rezo o la meditación. Se señaló que la mayor religiosidad de los más pobres no se traduce en mayor participación en misas o ritos en parte porque aquellos habitan en sectores rurales donde la falta de sacerdotes disminuye la frecuencia de celebraciones. En cambio, sí se reportó mayor práctica del rezo o meditación por parte de los menesterosos frente a los pudientes.

¿Qué se halló respecto de la felicidad? Esta fue calculada a partir de la escala de 0 a 20 (Mateu et al., 2020). Para quienes están en una posición

\footnotetext{
6 Tener en cuenta que el INEI incluyó a quienes simplemente respondieron "Cristianos" en la categoría "otra religión" como suele suceder con muchas Iglesias también llamadas evangélicas o protestantes. Esta categoría “otra religión” obtuvo 4,8\% pero no sabemos con precisión qué porcentaje dentro de ella corresponde al cristianismo.
} 
privilegiada, el promedio es 14.74 , mientras que el promedio para aquellos situados en las antípodas es $11.24^{7}$. Se trata de una diferencia significativa de más de 3 puntos $^{8}$. Para una visión más completa sobre el comportamiento del puntaje, véase Gráfico 1. En él se podrá visualizar, para cada grupo, qué valores toma el puntaje, con qué frecuencia ocurren, hacia qué valor tienden -media o promedio- y cuán dispersos están uno del otro con respecto su media -variancia. En resumen, si la escala hubiera sido hasta el 100, se diría que los ricos poseen una felicidad de 74 y los pobres de 56. Queda claro que los muy pobres, pese a ser muy religiosos, más incluso que los ricos, no alcanzan el nivel de felicidad de estos últimos, sean estos religiosos o no. En cada ítem examinado, como la práctica del rezo y la asistencia a misas o cultos, la felicidad de los privilegiados siempre es superior (Ibáñez et al., 2020).

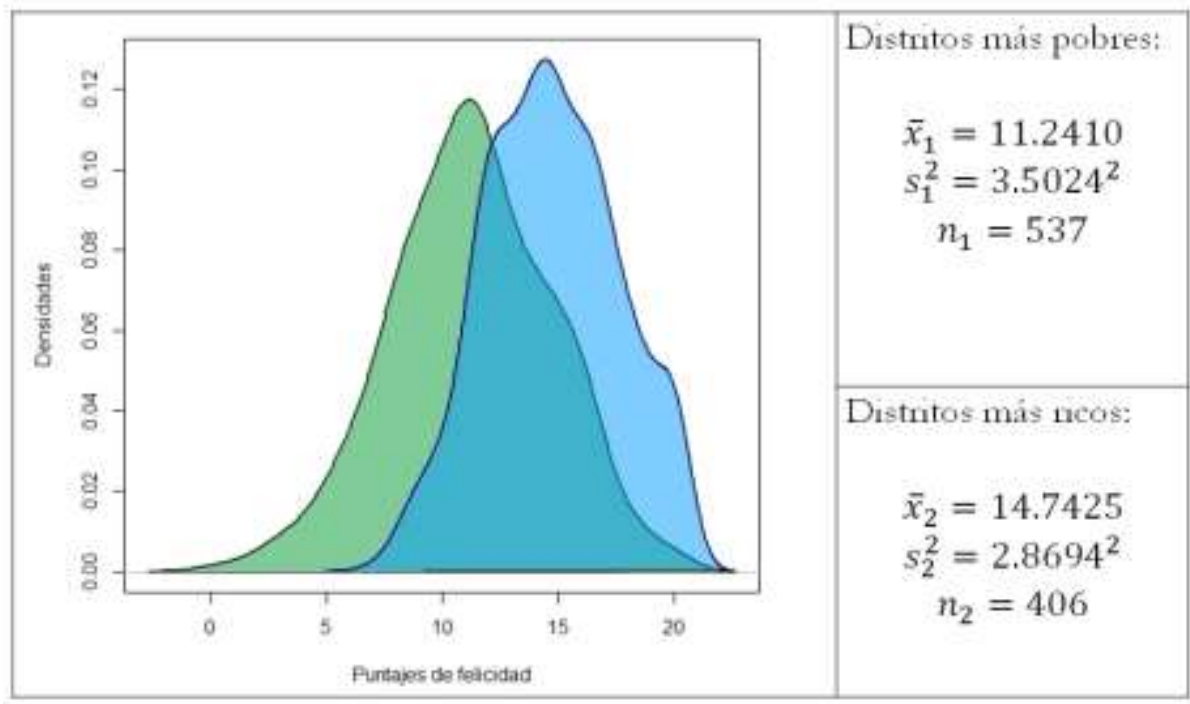

Gráfico 1. El comportamiento de los puntajes de felicidad para jefes de hogar en los distritos más pobres y más ricos del Perú Fuente: Encuesta FPV (2017). Elaboración propia.

\footnotetext{
$7 \quad$ Para esta afirmación se utilizan los promedios porque se tiene evidencia estadística de que la felicidad se distribuye normalmente, en ambos estratos, pobre y rico. Cuando se analice la felicidad para agrupaciones distintas, como se verá en la última sección al clasificar a las personas según algún tipo de pobreza espiritual, la medida estadística de referencia será la mediana.

8 No es propósito de este estudio establecer la magnitud estadística de esta diferencia, es decir, si es una diferencia pequeña, mediana o grande. En otro documento, los autores del presente artículo además analizan la relación entre felicidad y religiosidad para cada una de las variables como participación en ritos o frecuencia de rezo utilizando las medianas en vez de los promedios (Ibáñez et al., 2020).
} 
Por tanto, una lectura literal de la expresión evangélica "felices los pobres" no tendría sustento empírico si la frase se refiriese a aquellos identificados según el índice de pobreza monetaria utilizado para este estudio. El mismo hallazgo se reporta en los Informes Mundiales de Felicidad (Helliwell et. al., 2012; 2015; 2017). En ellos se reitera regularmente que las sociedades más prósperas económicamente gozan de promedios de felicidad más altos que aquellas en desarrollo. Ciertamente otros enfoques y metodologías discrepan, sean estas cuantitativas (Clifton, 2015) o cualitativas (Carrasquilla, 1996) ${ }^{9}$. Sin embargo, la mayoría de los estudios empíricos coinciden con el Informe Mundial de la Felicidad, que es el reporte internacional más reconocido y oficial, auspiciado por las Naciones Unidas. Entonces, para comprender la posible veracidad de aquella buena noticia para los pobres se hace necesario ir más allá de la pobreza económica hacia las formas en que el Evangelio, y particularmente las bienaventuranzas, parecen entenderla.

\section{LOS POBRES EN LAS BIENAVENTURANZAS SEGÚN GUTIÉRREZ}

Las interpretaciones sobre el binomio pobreza y riqueza son muy variadas desde la Biblia y particularmente en el Nuevo Testamento. Reseñemos dos. Por un lado, unos explican la carencia material como castigo para quienes desprecian los preceptos religiosos y la bonanza económica como recompensa para quienes los obedecen. Los autores que sostienen una lectura semejante del mensaje cristiano hoy están representados por la llamada teología de la prosperidad (Lindsay, 1960; Roberts \& Montgomery, 1966; Ziglar, 1975). Por otro lado, un grupo de autores interpreta el cristianismo desde la opción preferencial por los pobres. Para ellos, miembros de la llamada teología de la liberación, la pobreza contradice los designios de Dios por lo que la tarea del cristiano consiste en liberar a los pobres de su situación de opresión y sufrimiento (Boff, 2003; Gutiérrez, 1996).

En la Biblia las bienaventuranzas se presentan en dos versiones, una de Mateo y una de Lucas, que parecen opuestas en algunos aspectos esenciales. Principalmente interesa examinar cómo ambas comprenden la promesa o el anuncio de felicidad para los pobres. La versión de Lucas dice: "Felices los pobres porque de ustedes es el reino de Dios" (Lc 6,21), mientras que la de Mateo señala: "Felices los que tienen el espíritu del pobre porque de ellos es el reino de los cielos", o "pobres en espíritu”, o "pobres

\footnotetext{
9 En una breve nota, Clifton (2015) resume bien cómo es que algunos reportes ubican a países como Suiza o Finlandia en el top, mientras que otros más bien a los latinoamericanos. Por su parte, Carrasquilla (1996) a partir de entrevistas y trabajo de inserción sostiene que los pobres saben disfrutar o gozar la vida.
} 
de espíritu" (Mt 5,3). Ambos evangelios coinciden en que el reino y la felicidad son para los pobres, pero parecen discrepar sobre quién debe ser considerado tal. ¿Quién es el pobre que puede ser llamado bienaventurado? El análisis que sigue se apoya en la obra de Gustavo Gutiérrez (1991; 1994; 1996; 2010), padre de la teología de la liberación, movimiento que precisamente pusiera la pobreza al centro del debate teológico. Cabe advertir que, si bien la discusión se centra en la primera bienaventuranza, la interpretación de Gutiérrez incluye el significado de las demás.

El texto de Lucas señala que los destinatarios del Reino son "los pobres". Por la construcción de la frase y aplicando una lectura hermenéutica a los evangelios, Gutiérrez concluye que el significado es claro. La felicidad es para los comúnmente llamamos pobres: los que no tienen que comer, o vestir, y experimentan diversas necesidades materiales (1996). Cabe señalar que en la edición original de "Teología de la liberación" en 1971 la mención a la pobreza por momentos parece ambigua. En algunas partes del libro, se entiende principalmente como carencia de recursos o dificultad material, aunque también muchas menciones parecen comprenderla en sentido más amplio: como exclusión social. Posteriormente, Gutiérrez también ha precisado su comprensión de la pobreza para enfatizar que ella no solo es privación económica, sino también exclusión o insignificancia social $(1994 ; 2010)$. Ser poco respetado o valorado, por no decir humillado y marginado, constituyen también una forma de pobreza. Esta reflexión calzaría bien con los esfuerzos por expandir la comprensión de la pobreza como se ha realizado en las últimas décadas desde la economía con el enfoque del desarrollo humano (Iguíñiz, 2003; Sen, 2000) y el de la pobreza multidimensional (Alkire et al., 2015). En adelante, la versión de Lucas se denomina "pobreza real", para distinguirla del sentido figurativo de la expresión "pobreza espiritual” o "pobreza en espíritu” según la versión de Mateo.

La sección segunda de este artículo utilizó el sentido material de la pobreza para analizar su relación con la felicidad. Al haber utilizado un índice de pobreza monetaria, se ha identificado a los pobres con quienes carecen de medios económicos. La expresión de Lucas, que denominamos pobreza real, debiera entenderse no solo como carencia de medios, sino también como exclusión o marginación social. Gutiérrez sostiene que tanto para la tradición bíblica como para el mundo actual la exclusión es mayor que la desposesión material. La palabra griega que usa Lucas es ptojós. El término se refiere al pobre, al que no vale, al excluido. Es obviamente desposeído, pero más que eso. Es diferente de quien trabaja y gana poco. Para este estudio, en vez de identificar a los pobres desde un índice monetario, hubiera sido tal vez más adecuado uno de exclusión social. Pero no existe algo semejante para el Perú. Índices alternativos como el 
de desarrollo humano o de pobreza multidimensional no han sido aplicados al país como para determinar una escala o ranking de los distritos más pobres. Además, una versión estándar de estos dos índices tampoco recogería fielmente aquello que Gutiérrez denomina pobreza real o exclusión social. Por ello, a la sección segunda del artículo, donde se concluyó que la afirmación "felices los pobres" no tendría sustento empírico, debemos añadir que tal conclusión tiene sentido siempre que entendamos los límites para aplicar la noción pobreza real a un trabajo de campo como el que se hizo. Nuevamente, los mapas de pobreza disponibles por el INEI nos permiten identificar geográficamente cuáles son los distritos más pobres, o "los pobres entre los pobres", pero solo en sentido monetario. De allí que en la sección segunda se ha mostrado que los jefes de hogares ricos son más felices que los pobres.

Sin embargo, cabe mencionar la interpretación de Gutiérrez sobre el pasaje "felices los pobres porque de ellos es el Reino de los cielos" (Lc $6,21)$ entendiendo por estos a los pobres reales, los excluidos, o al menos a los pobres materiales. Dice Gutiérrez:

el Reino de Dios trae necesariamente consigo el restablecimiento de la justicia en este mundo, hay que pensar que Cristo declara bienaventurados a los pobres porque el Reino de Dios ha comenzado: 'Cumplido es el tiempo, y el reino de Dios está cercano’ (Mc 1,15). Es decir, se ha iniciado la supresión de la situación de despojo y pobreza que les impide ser plenamente seres humanos, se ha iniciado un Reino de Justicia, que va incluso más allá de lo que ellos podrían esperar. Bienaventurados son porque el advenimiento del Reino pondrá fin a su pobreza creando un mundo fraternal. (1996: 425-426)

Gutiérrez, en concordancia con la exégesis contemporánea, destaca la tensión entre el "ya pero todavía no" de la felicidad prometida a los pobres. La salvación ha llegado, pero aun queda un largo camino por recorrer. El cumplimiento de la promesa ha comenzado, pero su plenitud es escatológica. Dicha tensión entre presente y futuro se agudiza en la versión de Mateo, pues la primera bienaventuranza, precisamente aquella que interesa más al presente estudio, está en presente indicativo: ćotiu. En las otras bienaventuranzas, prima el futuro: "recibirán la Tierra", "serán saciados", etc. Pero en la primera se habla en tiempo presente. Es esa dimensión presente la que hemos intentado captar al menos parcialmente con el estudio de campo, aquella que podría ser asequible en nuestra experiencia histórica concreta, mientras que dejamos de lado aquella felicidad plena de carácter más bien trascendental.

Por su parte, la expresión de Mateo genera una amplia gama de lecturas. ¿Quién es un "pobre espiritual"? Incluso se percibe la discrepancia 
entre diferentes Biblias a las que tienen acceso las personas que fueron encuestadas. Por ejemplo, los Testigos de Jehová transcriben Mateo 5,3 del siguiente modo: "Felices son los que tienen conciencia de su necesidad espiritual, puesto que a ellos pertenece el reino de los cielos" ${ }^{\prime 10}$. El pobre espiritual sería una persona que, consciente de su lejanía de la palabra de Dios, decide enmendar su vida. En cambio, la mayoría de las biblias católicas utiliza expresiones como "pobres de espíritu" o "pobres en espíritu". Esta es la versión que seguimos para este estudio por cuatro razones. Primero, es más cercana al sentido literal desde las fuentes griegas: Maxáoı

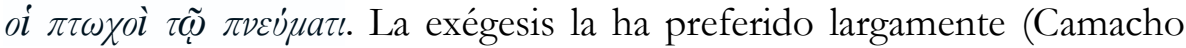
1986). Segundo, la mayor parte de la población autodenominada religiosa en Perú es católica, por lo cual sería mejor utilizar las versiones que han predominado en la religión de la población. Además, el catolicismo es transversal a todas las clases sociales y el estudio compara la felicidad entre los más ricos y los más pobres. Tercero, esta traducción da cuenta de una tensión histórica entre interpretaciones divergentes del mismo texto dentro del catolicismo y que, desde él, han influenciado otras versiones del cristianismo. Como se explicará en los siguientes párrafos, según Gustavo Gutiérrez, existen al menos dos posibles interpretaciones de la pobreza espiritual: una históricamente dominante y otra más reciente y propia de la Teología de la Liberación. Cuarto, esta escuela teológica nace en Latinoamérica precisamente para comprender el mensaje cristiano en un continente marcado por la injusticia social y las grandes disparidades. Este movimiento cobra vigor e influencia social desde la segunda mitad del siglo XX. El trabajo de campo de la Encuesta FPV (2017) recoge una población que de por sí es interesante contrastar con la visión de esta teología.

Volviendo a la tercera razón, Gustavo Gutiérrez señala dos ramas de interpretación respecto del término pobre espiritual. La primera, llamémosle "pobreza espiritual tradicional" (PET), ha sido muy difundida en la historia del cristianismo y todavía sigue vigente en muchos lugares. $\mathrm{Hu}-$ mildad y desprendimiento podrían ser sus valores centrales. En palabras de Gutiérrez, esta forma de pobreza espiritual se resume así: "con frecuencia, es vista como una simple actitud de desprendimiento frente a los bienes de este mundo. El pobre de este tipo sería, entonces, no tanto el que no posee bienes materiales, sino más bien aquel que -aunque los poseano está apegado a ellos" (1996: 412-413). De allí que un rico material podría ser un pobre espiritual; y, por el contrario, un pobre real o material podría ser un rico espiritual -apegado a bienes. El primero sería feliz; el segundo, no. Jesús felicita al pobre en espíritu, al margen de que sea pobre

10 https://www.jw.org/es/publicaciones/biblia/bi12/libros/mateo/5/ 
o rico en sentido económico. Gutiérrez señala que esta interpretación puede ser espiritualista. Un rico real que se dice a la vez pobre espiritual en aquellos términos no está necesariamente comprometido con la transformación social. En tanto que es una persona desprendida de lo material cabría esperar que fuera caritativo ante un pedido de auxilio, pero no siempre sucede así.

La segunda interpretación, sostenida por los teólogos de la liberación, es más reciente -del siglo veinte-, aunque ha estado presente de diverso modo en otras teologías y modos de acción pastoral ${ }^{11}$. Llamémosle "pobreza espiritual de la liberación" (PEL). Gutiérrez cree que el pobre espiritual es el discípulo, caracterizado ciertamente por poner su vida en manos de Dios, por tener a Dios como su riqueza o confiar en Él. Pero, además, Gutiérrez destaca un elemento que la interpretación anterior no recoge: la relación directa entre la pobreza espiritual del evangelio de Mateo, y la pobreza real del evangelio de Lucas. El abandono en las manos de Dios conlleva a un compromiso: la búsqueda de la justicia y la solidaridad para aquellos con quienes Dios mismo se ha identificado, los pobres. Si en Lucas se dice que los pobres reales son felices, es porque Dios ya está trabajando por y para ellos. Esa es su misión. Lo que la versión de Mateo estaría añadiendo es que los pobres espirituales o discípulos, están llamados a colaborar con esa misión: la liberación de los pobres reales. Entonces, una persona PEL, más que humilde o desprendida, es solidaria y preocupada por la justicia social.

\section{MidiENDO LA FELICIDAD DE LOS POBRES ESPIRITUALES}

Se ha definido así humildad y desapego económico como los valores centrales de una persona que suscribe la pobreza espiritual en sentido tradicional (PET); en cambio, justicia social y solidaridad, para quien suscribe la pobreza espiritual en sentido de la teología de la liberación (PEL). El siguiente paso consiste en su medición. ¿Cómo determinar a través del trabajo de campo si una persona corresponde a PET, o PEL, o ninguna de ellas, o ambas a la vez? Para ello, la Encuesta FPV (2017) incluyó algunas preguntas inspiradas en el Portrait Value Questionary (European Social Survey, 2016) que utiliza el marco general de Schwartz (2003). La teoría de Schwartz es ampliamente conocida para el estudio de valores, definir perfiles, realizar comparaciones interculturales, entre otros fines. Incluso el propio autor comenzó tempranamente a utilizar su teoría para identificar los valores de las personas religiosas (Schwartz \& Huismans, 1995).

11 Por ejemplo, los teólogos latinoamericanos señalan a Bartolomé de las Casas (14841566) como precursor de esta línea (Gutiérrez, 1990). 
Posteriormente ha sido aplicada por otros para definir el perfil de valores de las personas creyentes pese a pertenecer a diversas religiones, países y culturas. Por ejemplo, Saroglou, Delpierre \& Dernelle (2004) afirman que, de acuerdo con los valores listados por Schwartz, una persona religiosa tiende a ser más tradicional y menos abierta al cambio en comparación a un ateo.

Los valores de la teoría de Schwartz no se ajustaban a las preguntas de investigación planteadas en esta sección. Humildad, desapego, solidaridad y justicia, como se han definido para las personas PET y PEL, no están entre los valores que Schwartz lista, ni en el modo en que él los comprende. Sin embargo, algunas preguntas del Portrait Value Questionary (European Social Survey, 2016), inspiradas en Schwartz, sí eran cercanas a lo que se estaba buscando. Pese a no ser idénticas, se creyó conveniente emplearlas porque son preguntas bastante estandarizadas e incluyen la posibilidad de realizar eventuales comparaciones con data obtenida en otras latitudes.

Entonces, para medir el grado de pobreza espiritual en sentido tradicional (PET), se seleccionó las dos preguntas más cercanas que se hallaban en la Encuesta FPV. Primero, "¿Para usted es importante tener mucho dinero? ¿Quiere tener mucha plata y comprar cosas caras?”. Esta pregunta mide la ambición o apego material. Segundo, "¿Para usted ser humilde y sencillo es importante? ¿Trata de no ser creído [soberbio]?”. Esta pregunta mide la humildad. Ambas se responden en escala del 1 al 4 (nunca, pocas veces, muchas veces, siempre). Una persona PET será aquella que se identifica con las opciones 1 y 2 para la primera pregunta; y, 3 y 4 para la segunda.

Análogamente, para medir el grado de pobreza espiritual en sentido de la teología de la liberación, (PEL), se seleccionó las dos preguntas más cercanas que se encontraban en la Encuesta FPV. Primero, "¿Para usted es importante que todas las personas deban ser tratadas por igual? ¿Cree que todos deberían poder tener las mismas cosas?”. Esta pregunta se centra en el valor de la justicia social. Segundo, "¿Para usted ayudar a los demás es muy importante? ¿Usted se preocupa porque los demás estén bien?”. Esta pregunta se centra en el valor de la solidaridad. Ambas se responden en escala del 1 al 4 (nunca, pocas veces, muchas veces, siempre). Una persona PEL será aquella que se identifica con las opciones 3 y 4 de ambas preguntas.

Como se aprecia en el Gráfico 2, en escala de 0 a 20, las personas con valores PEL son más felices que las personas con valores PET en ambos grupos, pobres y ricos. Por un lado, dentro de los ricos la mediana de la felicidad de los PEL es 15.22 frente al 13.55 de los PET, una diferencia de casi 2 puntos. Por otro lado, dentro de los pobres la mediana de la felicidad 
de los PEL es 12.25 frente al 10.36 de los PET, nuevamente una diferencia de casi 2 puntos. En ambos casos es también mayor la felicidad de quienes son PEL que la de aquellos que son PET y PEL a la vez. El Gráfico 2 incluye tanto a las personas religiosas como a las que no lo son en absoluto. De todos modos, la conclusión, los PEL son más felices que los PET u otros, debe ser vista con cautela particularmente para el caso de los ricos pues algunos " $n$ " son pequeños ${ }^{12}$.

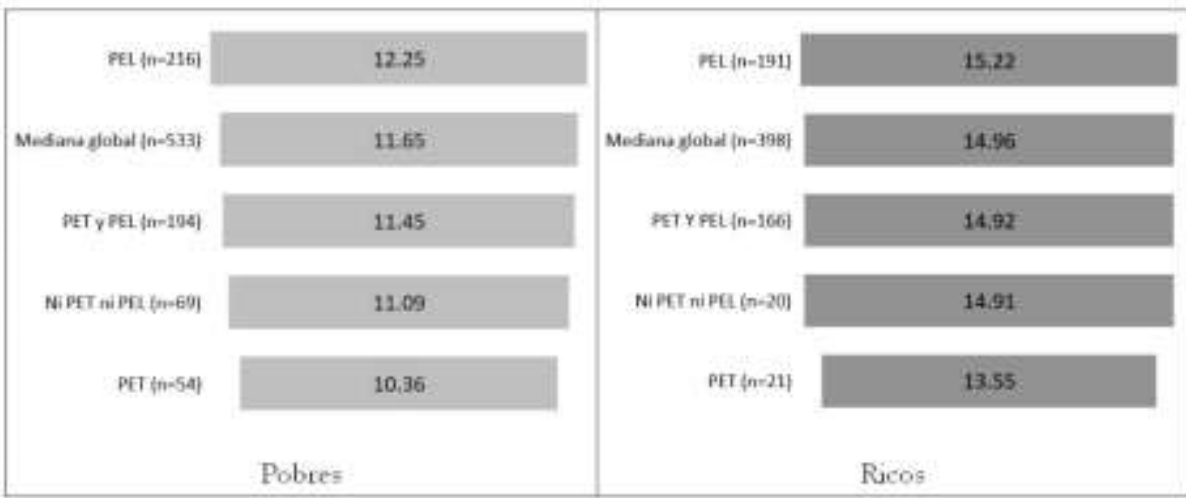

Gráfico 2. Puntajes de felicidad (medianas) para jefes de hogar PET y PEL en los distritos más pobres y más ricos del Perú incluyendo personas no religiosas.

Fuente: Encuesta FPV (2017). Elaboración propia.

En seguida se aplicó un filtro: solo se incluyó para este segundo ejercicio a las personas que consideran a Dios como muy importante en su vida, es decir, se seleccionó solo a las personas que marcaron 7 o más en escala del 1 al $10^{13}$. Este filtro se utilizó porque el presente artículo compara dos tipos de personas contrapuestas desde dos interpretaciones de la

12 Las afirmaciones o conclusiones se deben mirar con cautela cuando los " $n$ " o número de observaciones -en este caso entrevistados- son desproporcionados. Para el caso de los ricos, nótese que el número total de observaciones válidas era 398. Luego el " $n$ " de las personas que no son ni PET ni PEL -20 - o de las personas PET -21- son pequeños, en proporción casi de 1 a 8 , frente a los " $n$ " de las personas que son PEL 191- y de las que son PET y PEL a la vez -166. Lo ideal hubiera sido que la proporción no fuera mayor de 1 a 2 o que el número mínimo de " $n$ " de los primeros fuera 149 . No obstante, aun cuando exista una ligera diferencia en los tamaños de muestra de los dos grupos de comparación, cualquier conclusión estadística estará sujeta a una variación (incremento o reducción) del error tipo I (si originalmente era $\alpha=0.05$, este podría 0.03 ó 0.08. Para más detalles, ver Hopkins, Hopkins \& Glass (1996: 204-206).

13 Para este ejercicio se incluye a quienes se consideran muy religiosos en general, sin importar con qué Iglesia particular se identifiquen. En resumidas cuentas, la mayoría reportó ser católico o cristiano, pero lo que más cuenta es que las personas se conciban como muy religiosas. Mayor detalle se encuentra en Ibáñez et al. (2020). 
pobreza espiritual, la cual es una categoría religiosa. Sin este filtro de religiosidad, esos valores asignados pierden la dimensión espiritual y pasan a ser seculares. ¿Qué sucede cuando comparamos la felicidad de las personas PET y PEL, pero solo consideramos a las que se conciben muy religiosas? Como se aprecia en el Gráfico 3, el resultado es bastante similar al ejercicio anterior de la Tabla 1. Las personas religiosas con valores PEL son más felices que las personas religiosas con valores PET en ambos grupos, pobres y ricos. Por un lado, dentro de los ricos la mediana de la felicidad de los PEL es 15.31 frente al 13.40 de los PET, una diferencia de casi 2 puntos. Por otro lado, dentro de los pobres la mediana de la felicidad de los PEL es 12.28 frente al 10.39 de los PET, nuevamente una diferencia de casi 2 puntos. En ambos casos, es incluso mayor la felicidad PEL que la de aquellos que son PET y PEL a la vez. Para este caso la conclusión también debe examinarse con cuidado por el tamaño, particularmente pequeño de algunos "n" dentro de los jefes de hogar muy ricos.

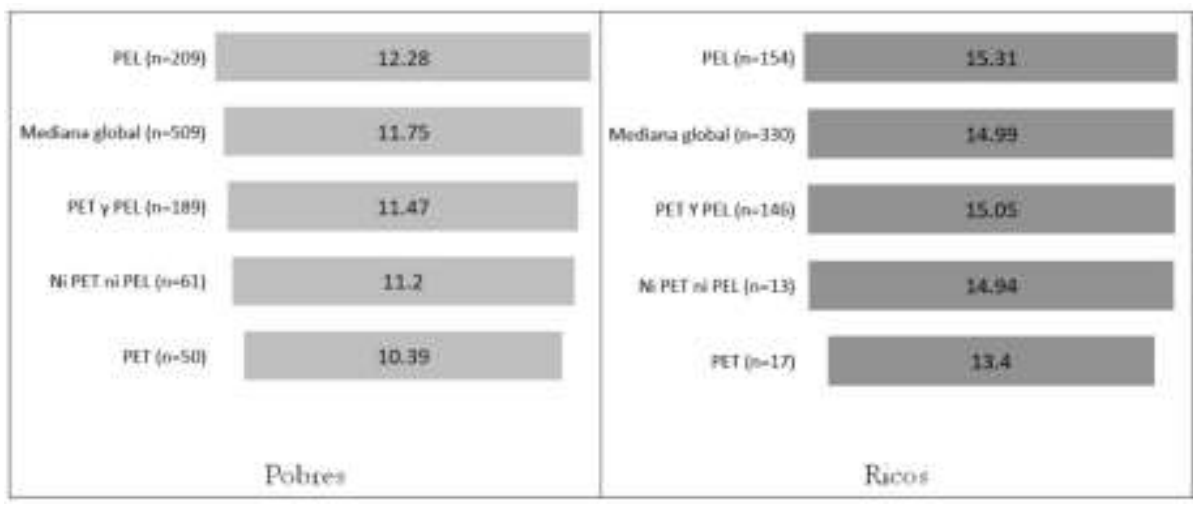

Gráfico 3. Puntajes de felicidad (medianas) para jefes de hogar PET y PEL en los en los distritos más pobres y más ricos del Perú incluyendo solo personas religiosas.

Fuente: Encuesta FPV (2017). Elaboración propia.

\section{CONCLUSIÓN GENERAL}

Es cierto que traducir las categorías pobre real y pobre espiritual a circunstancias y valores concretos y medibles cuantitativamente puede no captar todo el sentido de tales expresiones. Sin embargo, consideramos que lo fundamental ha sido recogido y, de ese modo, se ha prestado apoyo empírico para fortalecer algunos trabajos de interpretación teológica frente a otros.

El sentido literal de la expresión más seca de Lucas, "felices los pobres" (Lc 6,21), parece no ser empíricamente correcta. Los pobres reales, materialmente carentes y/o socialmente excluidos, no son tan felices 
como los ricos reales. Los primeros son tres puntos menos felices que los últimos en escala del veinte. Sin embargo, ello no descarta que el sentido de Lucas sea más bien una invitación a ver la vida como una promesa en cumplimiento: la buena noticia ha llegado sobre todo para quienes más la necesitaban, los pobres reales.

Por su parte, la expresión de Mateo, "felices los pobres de espíritu" (Mt 5,3), tiene sentido sobre todo en la interpretación propuesta por teología de la liberación frente a la teología más tradicional. Al menos es lo que el trabajo de campo confirmaría. La diferencia de casi dos puntos en escala de veinte se aprecia tanto si se compara a toda la muestra de jefes de hogares de cada estrato, pobre y rico, como si se aplica un filtro para seleccionar exclusivamente a quienes se consideran creyentes. Gutiérrez tendría razón al afirmar que la felicidad corresponde a quienes trabajan por acercar el Reino de Dios a los pobres reales.

\section{REFERENCIAS}

Abdel-Khalek, A. (2007). Religiosity, happiness, health, and psychopathology in a probability sample of Muslim adolescents. Mental Health, Religion \& Culture, 10(6), 571-583.

Abdel-Khalek, A. (2014). Happiness, health, and religiosity: significant associations among Lebanese adolescents. Mental Health, Religion \& Culture, 17(1), 30-38.

Alarco, G., Castillo, C. \& Leiva, F. (2019). Riqueza y desigualdad en el Perú: Visión panorámica. Lima: Oxfam.

Alkire, S., Foster, J., Ballon, P., Seth, S., Santos, M. E. \& Roche, J. M. (2015). Multidimensional poverty measurement and analysis. Oxford: Oxford University.

Aristóteles. (1985). Ética Nicomáquea. Madrid: Gredos.

Betz, H. D. (1995). The Sermon on the Mount Including the Sermon on the Plain (Matthew 5:3-7:27 and Luke 6:20-49). Minneapolis: Augsburg Fortress.

Boff, L. (2003). Jesus Cristo Libertador. Petrópolis: Editora Vozes.

Camacho, J. (1986). La proclama del Reino. Análisis semántico y comentario exegético de las Bienaventuranzas de Mt 5,3-10. Madrid: Cristiandad.

Carrasquilla, J. F. (1996). Escuchemos a los pobres. Aportes para una antropología del pobre. Bogotá: Indoamerican Press.

Cerda-Planas, C. (2019) Las potencialidades de la Teología Empírica para el desarrollo de una teología en diálogo con la experiencia religiosa actual. Teología y vida, 60(3), 367-394.

Clifton, J. (2015). Who Are the Happiest People in the World? The Swiss or Latin Americans? https://news.gallup.com/opinion/gallup/182843/happiest-people-world-swiss-latin-americans.aspx

Cox, H. \& Hammonds, A. (1989). Religiosity, aging, and life satisfaction. Journal of Religion and Aging, 5(1-2), 1-21. 
Deanis, W (1990). Empirical Tehology: A Revisable Tradition. Process Studies, 19(2), 85-102.

Dupont, J. (1969). Les Béatitudes, t. I. Le probléme littéraire. París: Gabalda.

Dupont, J. (1969). Les Béatitudes, t. II. La Bonne Nouvelle. París: Gabalda.

Dupont, J. (1973). Les Béatitudes, t. III. Les évangelistes. París: Gabalda.

Dupont, J. (1977). Introducción a las bienaventuranzas. Diakonia, (2), 45-53.

Ellison, C. (1991). Religious Involvement and Subjective Well-Being. Journal of Health and Social Behavior, 32(1), 80-99.

Epicuro. (2012). Obras completas. Madrid: Catedra.

European Social Survey. (2016). Source Questionaire. Round 8. 2016/2017. https://www.europeansocialsurvey.org/docs/round8/fieldwork/source/ESS8_source_questionnaires.pdf

Francis, L., Robbins, M. \& Astley, J. (2009). Empirical Theology in Texts and Tables. Brill: Leide - Boston.

Francis, L., Strathie, D., \& Ross, Ch. (2019). Reading the Beatitudes (Mt 5:1-10) through the lenses of introverted intuition and introverted sensing: Perceiving text differently. HTS Theological Studies, 75(4), 1-8.

García, C. (2011). Epicuro. Madrid: Alianza.

Greeley, A. \& Hout, M. (2006). The Truth about Conservative Christians. Chicago: University of Chicago Press.

Gundlach, E. \& Opfinger, M. (2013). Religiosity as a Determinant of Happiness. Review of Development Economics, 17(3), 523-539.

Gutiérrez, G. (1990). Dios o el oro de las Indias. Siglo XVI. Salamanca: Sígueme.

Gutiérrez, G. (1991). Pobres y opción fundamental. En I. Ellacuría y J. Sobrino. Mysterium Liberationis, Conceptos fundamentales de la teología de la liberación. (Tomo I, pp. 303-321). Madrid: Trotta.

Gutiérrez, G. (1994). El Dios de la vida. Salamanca: Sígueme.

Gutiérrez, G. (1996). Teología de la liberación. Perspectivas. Lima: CEP.

Gutiérrez, G. (2010). La opción preferencial por el pobre en Aparecida. Suplemento Progressio, (66), 37-48.

Hadaway, C. (1978). Life Satisfaction and Religion: A Reanalysis. Social Forces, 57(2), 636-643.

Hagner, D. (1993). Word Biblical Commentary Matthew 1-13. Dallas: Word books.

Helliwell, J., Layard, R. \& Sachs, R. (2012). World Happiness Report 2012. New York: The Earth Institute - Columbia University.

Helliwell, J., Layard, R. \& Sachs, R. (2015). World Happiness Report 2015. New York: The Earth Institute - Columbia University.

Helliwell, J., Layard, R. \& Sachs, R. (2017). World Happiness Report 2017. New York: The Earth Institute - Columbia University.

Hills, P. \& Argyle, M. (2002). The Oxford Happiness Questionnaire: a compact scale for the measurement of psychological well-breing. Personality and Individual Differences, 33, 1073-1082.

Hopkins, K. D., Hopkins, B. R., \& Glass, G. V. (1996). Basic statistics for the behavioral sciences. Needham Heights, MA: Simon \& Schuster Company. 
Ibáñez, F., Mateu, P., Vásquez, E., \& Zúñiga, J. (2020). Felicidad y religión en dos Perúes. Phainomenon, 19(2), 356-372.

Iguíñiz, J. (2003). Desarrollo, libertad y liberación en Amartya Sen y Gustavo Gutiérrez. Lima: Fondo Editorial de la PUCP, CEP e IBC.

INEI (2015). Mapa de pobreza provincial y distrital. Lima: INEI.

INEI (2018a). Resultados de la pobreza monetaria 2017. Lima: INEI. https://www.inei.gob.pe/media/cifras_de_pobreza/presentacion_evolucion-de-pobreza-monetaria-2017.pdf

INEI (2018b). Perú: Perfil sociodemográfico. Informe nacional. Lima: INEI.

Inglehart, R. (2010). Faith and Freedom: Traditional and Modem Ways to Happiness. En E. Diener, J. F. Helliwell, y D. Kahneman. International Differences in Well-Being (pp. 351- 397). New York: Oxford University Press.

Lefka, A. (2006). The Ancient Greek Concept of the Naturally Best Human Life. En K. Boudouris (Ed.). The Philosophy of Culture (vol. I, pp. 178-186). Athens: Ionia Publications.

Lim, C. \& Putnam, R. (2010). Religion, Social Networks, and Life Satisfaction. American Sociological Review, 75(6), 914-933.

Lindsay, G. (1960). God's Master Key to Prosperity. Dallas: Christ for the Nations Institute.

Mateu, P., Vásquez, E., Zúñiga, J., \& Ibañez, F. (2020). Happiness and Poverty in Very Poor Peru: Measurement Improvements and a Consistent Relationship. Qualtity \& Quantity, 54(3), 1075-1094.

Moberg, D. (1979). Spiritual Well Being: Sociological Perspectives. Washington D.C.: University Press of America.

Neyrey, J. (2005). Honor y vergüenza. Lectura cultural del Evangelio de Mateo. Salamanca: Sígueme.

Phan, R C. (1993) Experience and Theology: An Asian Liberation Perspective, Zeitschrift für Missionswissenschaft und Religionswissenschaft, 77, 99-121.

Platón (1988). Teeteto. En Diálogos (Vol. 5). Madrid: Gredos.

Platón (1981). Apología de Sócrates. En Diálogos (Vol. 1). Madrid: Gredos.

Pratt, J. (1920). Can Theology Be Made an Empirical Science? The American Journal of Theology, 24(2), 180-190.

Prasoon, R. \& Chaturvedi, K. R. (2016). Life Satisfaction: A literature Review. The Researcher-International Journal of Management Humanities and Social Sciences, $1(2), 25-32$.

Roberts, O. \& Montgomery, G. (1966). God's Formula for Success and Prosperity. Tulsa: Abundant Life Publication.

Saroglou, V., Delpierre, V., \& Dernelle, R. (2004). Values and religiosity: a metaanalysis of studies using Schwartz's model. Personality and Individual Differences, 37, 721-734.

Schickendantz, C (2017). Un enfoque empírico-teológico. En el método, el secreto de Medellín. Teología y vida, 58(4), 421-446.

Schwartz, S. H., \& Huismans, S. (1995). Value priorities and religiosity in four western religions. Social Psychology Quarterly, 58, 88-107. 
Schwartz, S. H. (2003). A proposal for measuring value orientations across nations. European Social Survey, 259-319. http://www.europeansocialsurvey.org

Sen, A. (2000). Desarrollo y libertad. Barcelona: Planeta.

Soydemir, G., Bastida, E. \& Gonzalez, G. (2004). The impact of religiosity on self- assessments of health and happiness: evidence from the US Southwest. Applied Economics, 36(7), 665-672.

Vásquez, E., Ibáñez, F., Mateu, P., \& Zúñiga, J. (2021). Los números de la Felicidad en dos Perúes. Lima: Universidad del Pacífico.

Veenhoven, R. (1997). Advances in Understanding Happiness. Revue Québécoise de Psychologie, 18, 29-74. 